\title{
NATURAL HISTORY OF STENOSIS IN THE ILIAC ARTERIES IN PATIENTS WITH INTERMITTENT CLAUDICATION UNDERGOING CLINICAL TREATMENT
}

Fernando Bocchino Ferrari, Nelson Wolosker, Ruben Aizyn Rosoky, Giuseppe D'Ippolito, Angela Maria Borri Wolosker and Pedro Puech-Leão

FERRARI FB et al. Natural history of stenosis in the iliac arteries in patients with intermittent claudication undergoing clinical treatment. Rev. Hosp. Clín. Fac. Med. S. Paulo 59(6):341-348, 2004.

PURPOSE: Inspite of the long experience with the treatment of intermittent claudication, little is known about the natural history of stenotic lesions in the iliac segment. With the advent of endovascular treatment, this knowledge has become important.

METHODS: Fifty-two stenosis, diagnosed using arteriography, in 38 claudicant patients were analyzed. After a minimum time interval of 6 months, a magnetic resonance angiography was performed to determine whether there was arterial occlusion.

The primary factors that could influence the progression of a stenosis were analyzed, such as risk factors (smoking, hypertension, diabetes, sex, and age), compliance with clinical treatment, initial degree of stenosis, site of the stenosis, and length of follow-up.

RESULTS: The average length of follow-up was 39 months. From the 52 lesions analyzed, 13 (25\%) evolved to occlusion. When occlusion occurred, there was clinical deterioration in $63.2 \%$ of cases. This association was statistically significant $(P=.002)$. There was no statistically significant association of the progression of the lesion with the degree or site of stenosis, compliance with treatment, or length of follow-up. Patients who evolved to occlusion were younger $(P=$ $.02)$. The logistic regression model showed that the determinant factors for clinical deterioration were arterial occlusion and noncompliance with clinical treatment.

CONCLUSIONS: The progression of a stenosis to occlusion, which occurred in $25 \%$ of the cases, caused clinical deterioration. Clinical treatment was important, but it did not forestall the arterial occlusion. Prevention of occlusion could be achieved by early endovascular intervention or with the development of drugs that might stabilize the atherosclerotic plaque.

KEYWORDS: Intermittent claudication. Natural history. Atherosclerosis. Iliacartery. Stenosis.

Atherosclerosis is an inflammatory disease with a slow evolution. It begins with thickening of the arterial wall, causing stenosis of the vessel lumen and, finally, arterial occlusion. ${ }^{1}$ However, accidents may occur in the atherosclerotic plaque, such as small ulcerations or ruptures that accelerate the occlusive process in an unpredictable way. ${ }^{2,3}$

In the lower limbs, intermittent claudication (IC) is the initial symptom of obstructive atherosclerosis. The great majority of patients with IC treated clinically respond satisfacto-

From the Department of Surgery and Division of Vascular Surgery, Hospital das Clínicas, Faculty of Medicine, University of São Paulo - São Paulo/ SP, Brazil.

E-mail: nwolosker@yahoo.com.br Received for publication on April 06, 2004. Accepted for publication on July 05, 2004. rily. ${ }^{4-7}$ When patients do not improve, there may be an indication for endovascular treatment if this is anatomically possible, especially for the aorto-iliac segment. ${ }^{8-10}$ Doubts still exist regarding the best therapeutic option over the long term. ${ }^{11-14}$

Despite wide experience with the treatment of IC, little is known about the natural evolution of stenotic lesions in the iliac segment. In the past, 
not much attention was given to more detailed studies of arterial stenosis in the lower limbs, since surgical treatment did not depend on the type of lesion (ie, occlusion or stenosis).

With the advent of endovascular treatment, knowledge of the natural history of stenosis became important, and some authors have been performing this type of study, especially in the superficial femoral artery. ${ }^{15}$ However, stenosis in the iliac arteries have not yet been studied, and this is exactly where endovascular treatment is most often performed and gives the best results. ${ }^{16}$

The goal of this study was to determine the natural evolution of stenosis in the iliac arteries and to compare this with the clinical evolution of patients.

\section{METHODS}

From January 1993 to December 2001, 1380 patients with intermittent claudication (IC) were admitted at our division. It is not our routine to prescribe an arteriography (AG) for patients with $\mathrm{IC},{ }^{17}$ but some patients are referred to us from other specialists and come with an arteriograph. From the patients with IC who had an arteriography, there were 38 with stenosis in iliac arteries. These 38 patients were prospectively surveyed.

This was a prospective, nonrandomized, and uncontrolled study. All patients underwent similar treatment, following the same protocol, in accordance with the ethical standards of the Committee of Ethics for Analysis of Research Projects on Human Experimentation and with the Helsinki Declaration of 1975 , as revised in 1983.

The average age was 63 years (ranging from 41 to 78 years); $21 \%$ were female and $79 \%$ male. The primary risk factors were smoking (92\%), arterial hypertension (39\%), and diabetes mellitus $(21 \%)$.

Patients who had already undergone surgical procedures in this vascular segment were not included in the study.

At the first visit, the extent of arterial occlusion was determined by physical examination (palpation of arterial pulses) and confirmed by the AG already performed. All patients had an ankle/brachial index of less than 0.8 , assessed with a Doppler ultrasound using a Vascular Minilab model 1050-C (Parks Medical Electronics, Inc Aloha, OR). Next, in order to objectively assess the severity of IC, we measured the maximum walking distance (MWD) on a progressive treadmill test using a motorized Trimline Model 2200.1 treadmill (Hebb Industries, Inc - Whitehouse, TX). This was done at a constant velocity of $3.2 \mathrm{~km} /$ $\mathrm{hr}$ initially on the level (0 degrees) and then with a progressive increase of $2 \%$ in the inclination every 2 minutes. The test was performed until pain prevented the patient from continuing to walk.

A program of physical activity, consisting of walking for 40 minutes per day, 4 times a week, was prescribed. Patients were instructed to continue to walk after the onset of typical pain but before the pain reached its maximum intensity. At this point they were to rest until pain abated and then start walking again to complete the time required.

Patients were carefully instructed in person by the authors regarding the benefits of exercise training. Also, they were encouraged to stop smoking and instructed about the benefits of doing so. No patient was given any type of pharmacological therapy, such as vasodilators or pentoxifylline, but those who were using antiplatelet therapy for cardiac diseases were instructed to continue it. Hypertension, diabetes, and hyperlipidemia, when present, were always treated by the clinical physician.

Patients were reevaluated after 3 months, 6 months, and every 6 months thereafter. Follow-up time ranged from 1 to 106 months, with an average of 39 months. At each visit, the treadmill test was performed and the MWD determined. The minimum time interval between the first and last evaluations was 6 months, except for 2 patients who, within this period of time, presented with clinical deterioration necessitating a new arteriography for surgical intervention.

At the last evaluation, in addition to the clinical analysis and walking test, a magnetic resonance angiography was performed using a gadolinium injection to determine whether there was occlusion of the vessel studied.

The first and the last evaluations were used for this study.

Regarding the analysis of the arteriography, the stenosis sites were identified as the common iliac artery (CIA) or external iliac artery (EIA). The degree of stenosis $(<70 \%$ or $>70 \%)$ was obtained by dividing the arterial measurement at the stenosis site by the average of the measurements made at locations immediately proximal and distal to the stenosis.

Regarding the analysis of the gadolinium magnetic resonance angiography, whether there was occlusion of the vessel studied or not was determined.

We defined 3 types of clinical evolution based on the treadmill test, as follows:

1. Improvement - an increase greater than or equal to $20 \%$ of the initial distance.

2. Stability - maintenance of the initial distance with a variation of up to $20 \%$.

3. Deterioration - reduction greater than or equal to $20 \%$ of the initial distance.

Compliance with treatment was de- 
termined based on patient reporting. We considered patients to be compliant with treatment when they kept their risk factors under control and performed the prescribed exercises.

The data were primarily analyzed using the chi-square test or Fisher's exact test, depending on the number obtained in each group. Statistical significance was declared at the 5\% $(P$ $<.05)$ level. The primary factors that could influence the progression of a stenosis were analyzed, such as risk factors (smoking, hypertension, diabetes, sex, and age), compliance with clinical treatment, initial degree of stenosis, site of the stenosis, and length of follow-up.

Afterwards, a logistic regression test was performed using the following variables: occlusion, site of occlusion, degree of stenosis, compliance with treatment, and clinical evolution.

\section{RESULTS}

The average length of follow-up was 39 months and ranged from 1 to 106 months. There was no association between occlusion and the length of observation.

Regarding the distribution of stenosis, $73 \%$ of the lesions were in the common iliac artery (CIA) and $27 \%$ were in the external iliac artery (EIA). Regarding the extent of stenosis, $48 \%$ were greater than or equal to $70 \%$ occluded.

There was no association between the progression of the stenosis and the risk factors (sex, smoking, hypertension, and diabetes), as shown in Table 1.

There was an improvement in the walking distances in $47 \%$ of the patients, 24\% remained stable, and 29\% worsened with clinical treatment. Twenty-five patients (66\%) were considered compliant with the treatment. Of these, 21 (84\%) presented a clinical course with an improvement or that was unchanged, and 4 (16\%) worsened. This result was statistically significant $(P=.02)$.

There was an improvement in the walking distances in $47 \%$ of the patients, $24 \%$ remained stable and $29 \%$ worsened with clinical treatment. Twenty-five patients (66\%) were considered compliant with the treatment. Of these, $21(84 \%)$ presented a clinical course with an improvement or that was unchanged, and 4 (16\%) worsened. Thirteen patients $(34 \%)$ were considered non-compliant with the treatment. Of these, $6(46 \%)$ presented with a clinical course with an improvement or that was unchanged, and $7(64 \%)$ worsened. This result was statistically significant $(\mathrm{p}=0.02)$.

The clinical course of patients was significantly related to the progression of their stenosis to occlusion (Table 2). Of the 52 lesions analyzed, 13 (25\%) evolved to occlusion. When an occlusion occurred, there was clinical deterioration in the majority of cases (63.2\%). This association was statistically significant $(P=.002)$ when compared to the cases that did not evolve to occlusion.
Figure 1 shows a 69 year old patient with a patent iliac stenosis before and after clinical treatment. In contrast, Figure 2 shows a 41 year old patient with a complete occlusion of a previously stenotic artery.

There was no statistically significant relationship between the progression of stenosis to occlusion and degree of stenosis $(P=.42)$, stenosis site $(P=.29)$, or compliance to treatment $(P=.74)$.

The average age of the patients who evolved to occlusion was 57.4 years, while this age was 63.4 years for patients who did not evolve to occlusion. This result was statistically significant $(P=.02)$.

In the first logistic regression model, utilizing clinical evolution as the dependent variable, 2 factors were shown to be determinants of clinical deterioration: arterial occlusion and noncompliance with treatment, as shown in Table 3. The importance of these factors is clear, as shown in Table 3 . If there was progression of a stenosis to occlusion in a patient who did not have adequate clinical treatment, the probability of clinical deteriora-

Table 1 - Relation between the risk factors and the progression of the stenosis.

\begin{tabular}{lcccc}
\hline Risk Factors & $\begin{array}{c}\text { Progression of Stenosis } \\
\text { Occlusion }\end{array}$ & Non-Occlusion & Total & $\mathrm{p}$ \\
\hline Male & 10 & 20 & 30 & \\
Female & 1 & 7 & 8 & $\mathrm{p}>0,05$ \\
Smoking & 10 & 25 & 35 & \\
Non-Smoking & 1 & 2 & 3 & $\mathrm{p}>0,05$ \\
Hypertension & 3 & 12 & 15 & \\
Non-Hypertension & 8 & 15 & 23 & $\mathrm{p}>0,05$ \\
Diabetes & 1 & 7 & 8 & $\mathrm{p}>0,05$ \\
Non-Diabetes & 10 & 20 & 30 & \\
\hline
\end{tabular}

Table 2 - Clinical course of patients in relation to the evolution of their stenosis.

\begin{tabular}{lccc}
\hline & \multicolumn{2}{c}{ Clinical Course } & \\
Evolution of the stenosis & Improved or unchanged & Deteriorated & Total \\
\hline Oclusion & 4 & 9 & 13 \\
Non-oclusion & 34 & 5 & 39 \\
Total & 38 & 14 & 52 \\
\hline
\end{tabular}




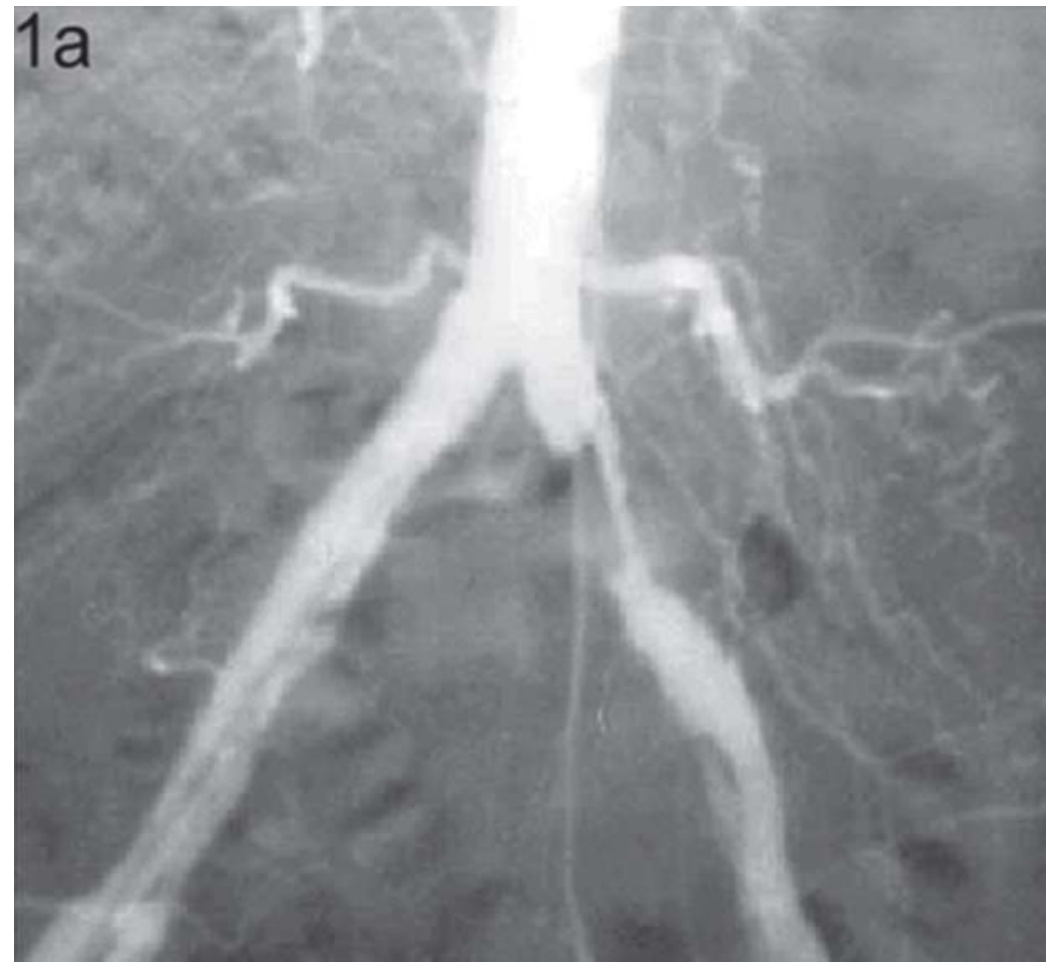

Figure 1a - Sixty nine year old man. Arteriography with critical stenosis in common iliac arteries.

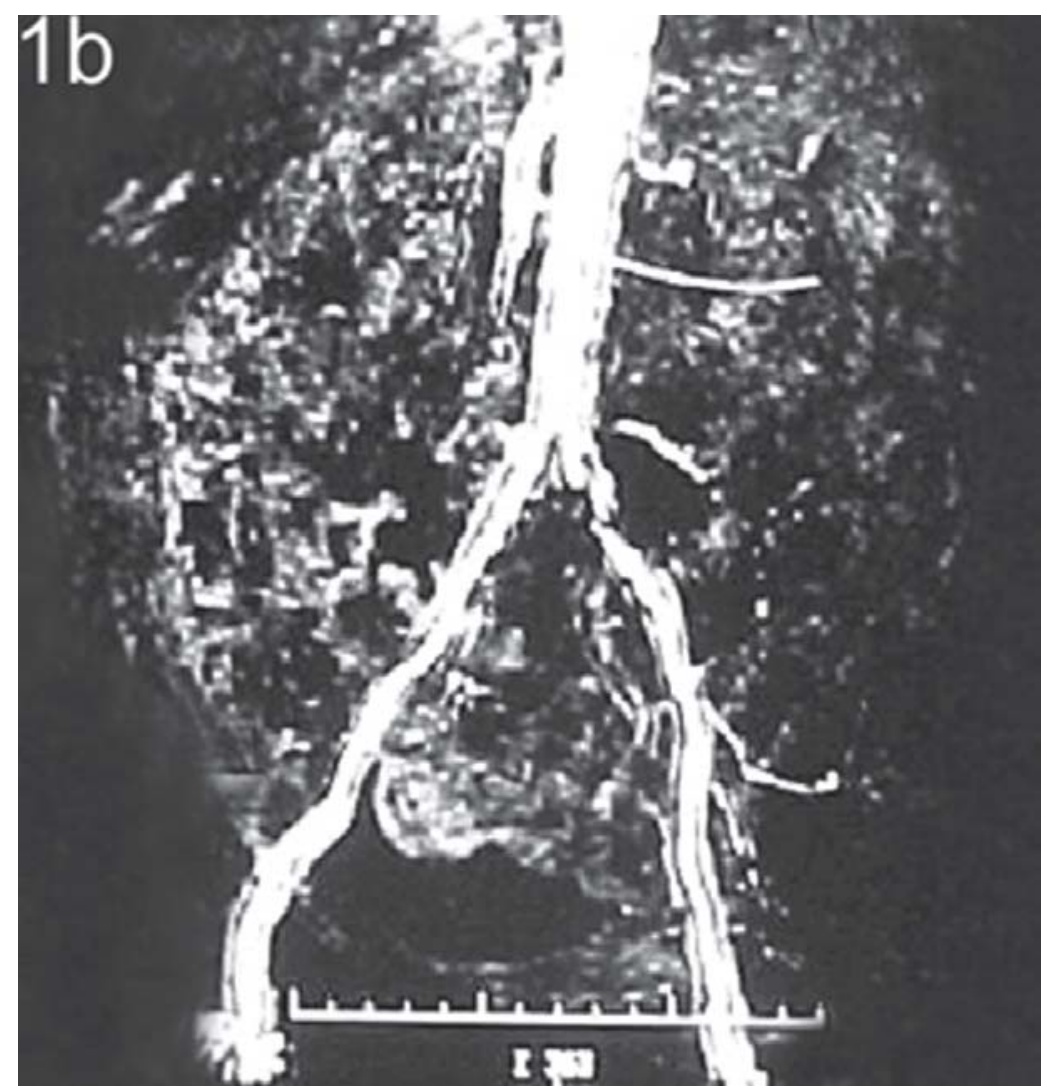

Figure 1b - Sixty months later, without occlusion and clinical improvement. tion was $88.2 \%$. On the other hand, if there was no occlusion and the treatment was adequate, this probability fell to $5.2 \%$.

In the second logistic regression model, utilizing arterial occlusion as the dependent variable, the only statistically significant association was with clinical evolution. On the basis of the observed results, it can be seen that for a patient with stenosis of any degree who presented with clinical worsening, the probability that thrombosis of a vessel had occurred was $64.3 \%$. If a patient showed clinical improvement or was stable, the probability that the vessel had occluded was $10.5 \%$.

\section{DISCUSSION}

Intermittent claudication of the Iower Iimbs usually hinders the patient's habitual activities, and the objective of treatment is to improve the quality of life. ${ }^{18}$

Initial treatment is always conservative because IC has a good prognosis. With conservative treatment, most of the patients show improvement or stability of the clinical manifestations ${ }^{5,19}$ with low risk of amputation. In our service, the patients undergo conservative treatment for at least 6 months as follows: nonsupervised physical exercises with 1 hour of daily walking ${ }^{20}$ and control of the primary atherosclerotic risk factors (smoking, hypertension, diabetes, and hyperlipidemia).

Surgical or endovascular treatment is only indicated when clinical treatment is not effective (critical ischemia or limiting IC). ${ }^{21-23}$

Patients with IC and stenosis in the iliac arteries form a group that poses some problems for the vascular surgeon. Should the patient be followed with only clinical treatment or should the lesion be surgically treated before 


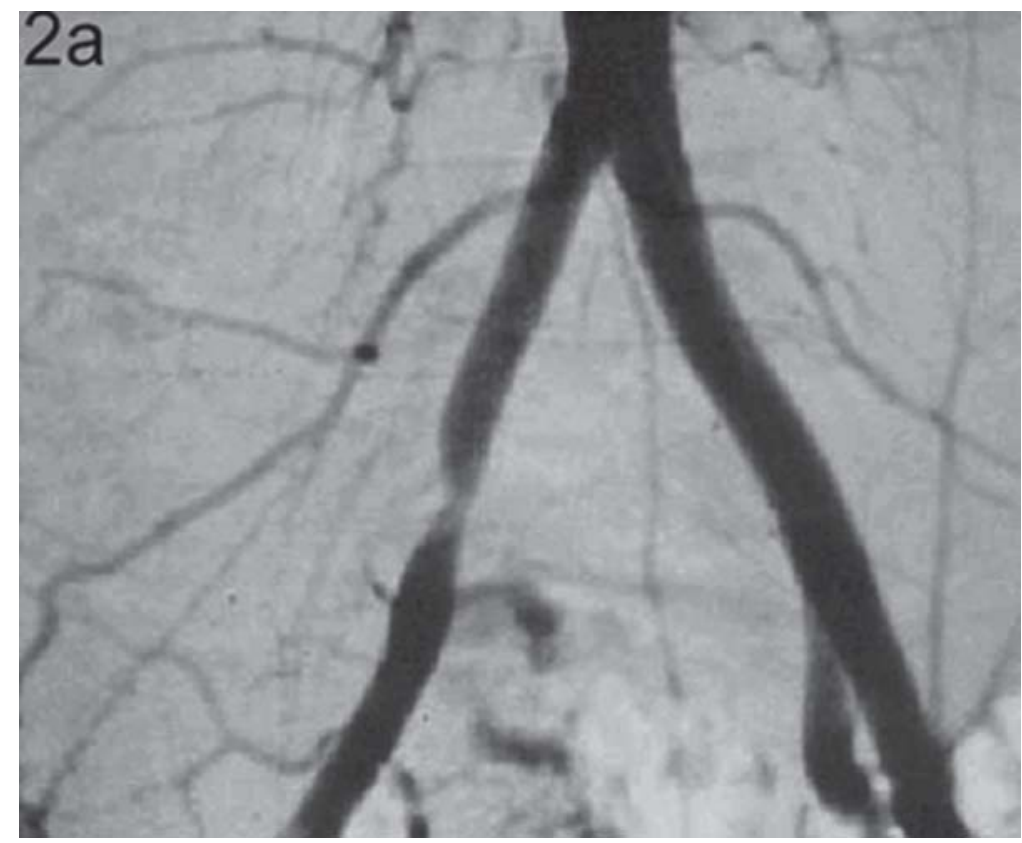

Figure 2a - Forty one year old man. Arteriography with critical stenosis in right common iliac artery.

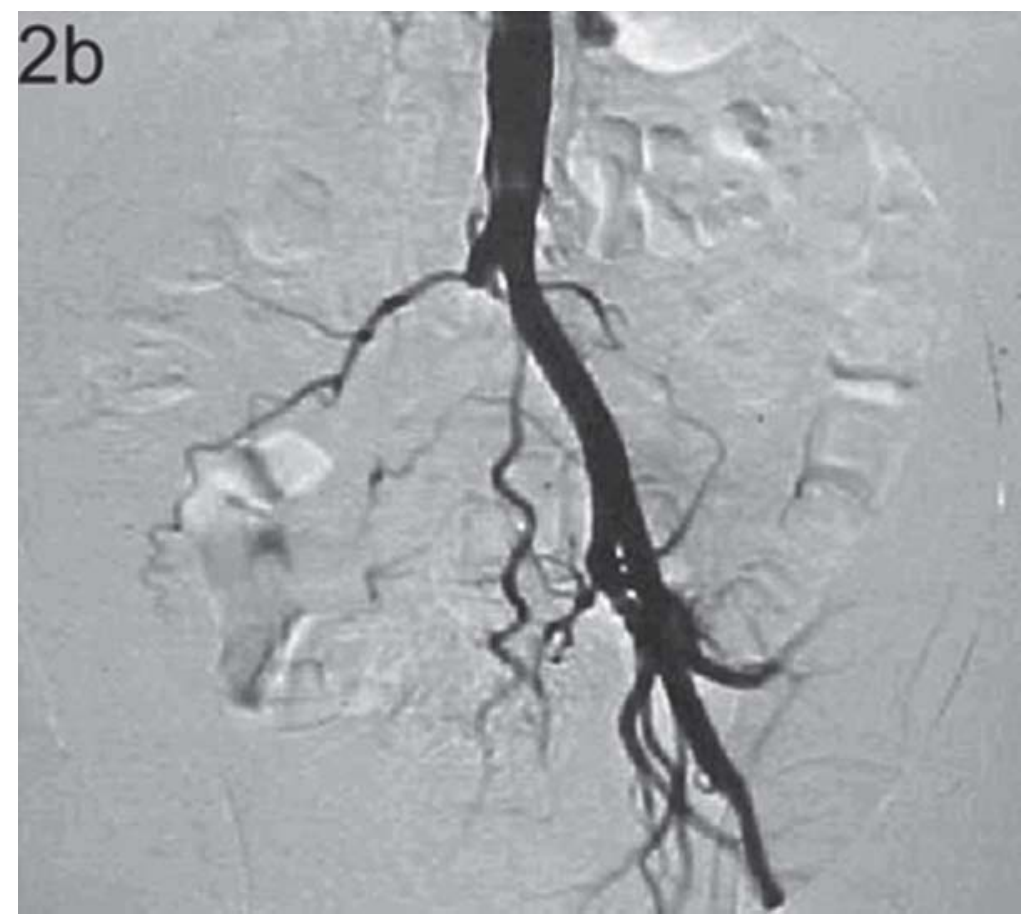

Figure 2b - Twenty nine months later, iliac occlusion with clinical deterioration.

Table 3 - Determinant factors for clinical deterioration.

\begin{tabular}{llc}
\hline Occlusion & Treatment & Probability of clinical deterioration \\
\hline Present & Non-compliant & $88.2 \%$ \\
Present & Compliant & $53.0 \%$ \\
Absent & Non-compliant & $26.5 \%$ \\
Absent & Compliant & $5.2 \%$ \\
\hline
\end{tabular}

it can evolve to a thrombosis?

There are studies showing that claudicating patients with stenosis have a worse prognosis than do those with total occlusion of the vessel, since there is a greater risk of progression of the lesion. ${ }^{24}$

The possibility of endovascular treatment, which produces better results in stenosis than occlusions, emphasizes the importance of having a better knowledge of these lesions. When occlusion occurs, the proximal and distal depositions of thrombi make the endovascular treatment more difficult or even impossible.

The choice of diagnostic method is one of the greatest challenges in studying stenosis in the iliac arteries. Arteriography is considered the gold standard for quantifying stenosis; however, arteriography is an invasive procedure that should not be requested unless there is a convincing clinical justification. ${ }^{16,25}$ Among the less invasive methods, the duplex scan presents some limitations in the iliac region because of difficulties in viewing the whole arterial segment and precisely quantifying the stenosis in some situations. ${ }^{26}$ Magnetic resonance angiography (MRA) is a relatively new method that is being refined and very probably will substitute for arteriography in most cases. Although it is still not very precise for quantifying stenosis, ${ }^{27,28}$ it offers security in the diagnosis of complete occlusions, which is the reason why this method was chosen. ${ }^{29}$ Both duplex scans and MRA were used in this study because MRA can only be used to determine whether the vessel is occluded, and not to measure the degree of occlusion.

Arteriography is not our routine procedure for IC. However, the patients included in this study were referred to us from other hospital services that had already performed the examination. Thus, it was possible to perform this clinical study making use of this impor- 
tant information - that is, the initial degree of stenosis as revealed by AG. For this reason, from among over 1300 patients presenting with IC, only 38 (those having undergone preliminary $\mathrm{AG}$ ) were included in this study.

Clinical treatment produced a satisfactory response, since $71 \%$ of the patients maintained or increased their walking distance. There was an association between clinical evolution and compliance with treatment, showing that patients who correctly followed the guidance had a better prognosis, which has already been reported in the literature.$^{30}$ However, there was no association between compliance with treatment and progression of the stenosis, showing that clinical treatment does not forestall arterial occlusion.

Walsch et al., ${ }^{14}$ studying the natural evolution of stenosis in the superficial femoral arteries, observed that after an average period of 37 months, there was no progression of the lesion in $72 \%$ of the patients and that there was a clear relationship between the progress of the disease and clinical deterioration. In the iliac arteries, we observed a similar result, since after an average length of observation of 39 months, $25 \%$ of the stenosis progressed to occlusion, with the majority of these patients $(69.2 \%)$ demonstrating clinical deterioration.

During the observation period, 5 patients in our series developed critical ischemia, 4 with occlusion of the iliac artery and 1 with progression of the lesion in the femoropopliteal region. All these patients underwent conventional surgical revascularization, with 2 of them undergoing amputation of toes.

The absence of an association between occlusion and degree of stenosis (greater or less than 70\%) indicates that the evolution of a stenosis to a thrombosis probably takes place because of a destabilization of the atherosclerotic plaque and not because of the gradual progression of the stenosis. Another factor that reinforces this hypothesis is the absence of a relationship between occlusion and length of observation. There were patients with critical stenosis (greater than $70 \%$ ) who were followed up for more than 5 years without progression of the lesion and who showed significant clinical improvement, just as there were patients with discrete stenosis who, within less than 6 months, presented with arterial thrombosis and critical ischemia.

The relationship between age and clinical evolution appears to confirm the fact, already cited in the literature, that atherosclerotic disease is more aggressive among younger individuals, ${ }^{31}$ which may perhaps justify earlier intervention, especially among this group of patients. ${ }^{32}$

The determinant factors for the clinical deterioration of patients were noncompliance with treatment and the occlusion of the vessel. The benefits of clinical treatment are already well known, and advice about these benefits should always be given. Nonetheless, such treatment does not prevent vessel occlusion, and if this occurs, deterioration may occur in more than $50 \%$ of patients.

Since our primary objective is to avoid clinical deterioration, one important strategy would be to avoid the progression of stenosis to occlusion. This could eventually be achieved either by early endovascular intervention or with the development of drugs that may stabilize the atherosclerotic plaque.

\section{RESUMO}

FERRARI FB e col. Evolução natural das estenoses nas artérias ilíacas em pacientes com claudicação intermitente submetidos a tratamento clínico. Rev. Hosp. Clín. Fac. Med. S. Paulo 59(6):341-348, 2004.

OBJETIVO: Apesar da longa experiência com o tratamento da Claudicação Intermitente, pouco se sabe sobre a evolução natural das estenoses nas artérias ilíacas. Com o advento do tratamento endovascular, esse conhecimento tornou-se importante.
MÉTODOS: Foram avaliadas cinqüenta e duas estenoses, diagnosticadas por arteriografia, em 38 pacientes com claudicação intermitente acompanhados clinicamente. Após um intervalo de tempo mínimo de 6 meses, os pacientes foram submetidos a uma angioressonância para determinar se houve oclusão arterial.

Principais medidas de avaliação: Foram avaliados os principais fatores que poderiam influenciar a progressão da estenose, como os fatores de risco (tabagismo, hipertensão, diabete, sexo, idade), a aderência ao tratamento clínico,o grau de estenose inicial, sua localização e o tempo de observação.

RESULTADOS: O período médio de observação foi de 39 meses. Das 52 lesões analisadas, 13 (25\%) evoluíram para oclusão. Quando houve oclusão, ocorreu piora clínica na maioria dos casos $(63,2 \%)$, sendo esta associação estatisticamente significante $(\mathrm{p}=0,002)$. $\mathrm{O}$ grau de estenose inicial, sua localização, a aderência ao tratamento e o tempo de observação não apresentaram relação com a progressão da lesão. Os pacientes 
que evoluíram para oclusão eram mais jovens $(\mathrm{p}=0,02)$. Pelo teste de regressão logística, os fatores determinantes da piora clínica foram a oclusão do vaso e a não aderência ao tratamento clínico.

CONCLUSÕES: A progressão da estenose para oclusão, que ocorre em $25 \%$ dos casos, gera piora clínica. O tratamento clínico, apesar de importante, não preveniu a oclusão arterial, que poderá ser alcançada com o desenvolvimento de drogas que possam estabi- lizar a placa aterosclerótica ou com intervenções endovasculares precoces.

UNITERMOS: Claudicação intermitente. Evolução natural. Aterosclerose. Artéria ilíaca. Estenoses.

\section{REFERENCES}

1 Ross R. Atherosclerosis: an inflammatory disease. N Engl J Med 1999;340(2):115-26.

2 Mecley M, Rosenfield K, Kaufman J, Langevin RE Jr, Razvi S, Isner JM. Atherosclerotic plaque hemorrhage and rupture associated with crescendo claudication. Ann Int Med 1992; 117(8):663-6.

3 Fuster V, Stein B, Ambrose JA, Badimon L, Badimon JJ, Chesebro $\mathrm{JH}$. Atherosclerotic plaque rupture and thrombosis. Evolving concepts. Circulation 1990;82(3):47-59

4 Wolosker N, Nakano L, Rosoky RA, Puech-Leao P. Evaluation of walking capacity over time in 500 patients with intermittent claudication who underwent clinical treatment. Arch Intern Med 2003;163:2296-2300.

5 Cronenwett JL, Warner KG, Zelenock GB, Whitehouse WM Jr, Graham LM, Lindenauer M, Stanley JC. Intermittent claudication: current results of non-operative management. Arch Surg 1984;119:430-36.

6 Imparato AM, Kim GE, Davidson T, Crowley JG. Intermittent claudication: its natural course. Surgery 1975;78(6):795-799.

7 Gardner AW, Poehlman ET. Exercise rehabilitation programs for the treatment of claudication pain. A meta-analysis. JAMA 1995;274(12):975-80.

8 Johnston KW, Rae M, Hogg-Johnston SA, Colapinto RF, Walker PM, Baird RJ, Sniderman KW, Kalman P. Five-year results of a prospective study of percutaneous transluminal angioplasty. Ann Surg 1987;206:403-13.

9 Whyman MR, Ruckley CV, Fowkes FGR. Angioplasty for mild intermittent claudication. Br J Surg 1991;78:643-45.

10 Whyman MR, Fowkes FG, Kerracher EM, Gillespie IN, Lee AJ, Housley E, Ruckley CV. Is intermittent claudication improved by percutaneous transluminal angioplasty? A randomized controlled trial. J Vasc Surg 1997;26(4):551-557.

11 Creasy TS, McMillan PJ, Fletcher EW, Collin J, Morris PJ. Is percutaneous transluminal angioplasty better than exercise for claudication? Preliminary results from a prospective randomized trial. Eur J Vasc Surg 1990;4:135-40.

12 Perkins JM, Collin J, Creasy TS, Fletcher EW, Morris PJ. Exercise training versus angioplasty for stable claudication: long and medium term results of a prospective, randomised Trial. Eur J Vasc Endovasc Surg 1996;11:409-13.
13 Whyman MR, Fowkes FG, Kerracher EM, Gillespie IN, Lee AJ, Housley E, Ruckley CV. Randomised controlled trial of percutaneous transluminal angioplasty for intermittent claudication. Eur J Vasc Endovasc Surg 1996;12:167-172.

14 Lundgren F, Dahllof AG, Lundholm K, Schersten T, Volkmann R. Intermittent claudication: surgical reconstruction or physical training? Ann Surg 1989;209(3):346-55.

15 Walsh DB, Gilbertson JJ, Zwolak RM, Besso S, Edelman GC, Schneider JR, et al. The natural history of superficial femoral artery stenosis. J Vasc Surg 1991;14(3):299-304.

16 Tegtmeyer CJ, Hartwell GD, Selby JB, Robertson R Jr, Kron IL, Tribble CG. Results and complications of angioplasty in aortoIliac disease. Circulation 1991;83(2):53-9.

17 Wolosker N, Rosoky RA, Nishinari K, Nakano L. Use of arteriography for the initial evaluation of patients with intermittent lower limb claudication. Sao Paulo Med J 2001; 119(2):59-61

18 Currie IC, Wilson YG, Baird RN, Lamont PM. Treatment of intermittent claudication: the impact on quality of life. Eur J Endovasc Surg 1995;10:356-61.

19 McAllister FF. The fate of patients with intermittent claudication managed nonoperatively. Am J Surg 1976;132:593-5.

20 Hiatt WR, Regensteiner JG, Hargarten ME, Wolfel EE, Brass EP. Benefit of exercise conditioning for patients with peripheral arterial disease. Circulation 1990;81:602.

21 Conte MS, Belkin M, Donaldson MC, Baum P, Mannick JA, Whittemore AD. Femorotibial bypass for claudication: do results justify an aggressive approach? J Vasc Surg 1995; $21: 873-81$

22 Zannetti S, L'Italien GJ, Cambria RP. Function outcome after surgical treatment for intermittent claudication. J Vasc Surg 1996;24:65-73.

23 Wolosker N, Nakano L, Anacleto MM, Puech-Leao P. Primary utilization os stents in angioplasty of superficial femoral artery. Vasc Endovasc Surg 2003;37:271-277.

24 Matsubara J, Ohta T, Sakurai T, Yamada I. Natural history of intermittent claudication in the Japanese. Jpn J Surg 1986; $16(1): 42-5$.

25 Waugh JR, Cacharias N. Arteriographic complications in the DSA era. Radiology 1992;182:243-6. 
26 Mullgan SA, Matsuda T, Lanzer P, Gross GM, Routh WD, Keller FS, et al. Peripheral arterial occlusive disease: prospective comparison of MR angiography and color duplex US with conventional angiography. Radiology 1991;178:695-700.

27 Cambria RP, Kaufman JA, L'Italien GJ, Gertler JP, LaMuraglia GM, Brewster DC, et al. Magnetic resonance angiography in the management of lower extremity arterial occlusive disease: a prospective study. J Vasc Surg 1997;25(2):380-89.

28 Hertz SM, Baum RA, Owen RS, Holland GA, Logan DR, Carpenter JP. Comparison of magnetic resonance angiography and contrast arteriography in peripheral arterial stenosis. MRA 1993;166:112-16.
29 Wolosker N, Nakano L, D’Hippolito G, Rosoky RA, Borri ML, Wolosker AM. Gadoliniun magnetic angioresonance in the study of aortoiliac disease. Angiology 2003;54(2):163-8.

30 Lasen OA, Lassen NA. Effect of daily muscular exercise in patients with intermittent claudication. Lancet 1966;2(7473):1093-6.

31 McCready RA, Vincent AE, Schwartz RW, Hyde GL, Mattingly SS, Griffen WO Jr. Atherosclerosis in the young: a virulent disease. Surgery 1984;96(5):863-68.

32 Valentine RJ, MacGillivray DC, DeNobile JW, Snyder DA, Rich NM. Intermittent claudication caused by atherosclerosis in patients aged forty years and younger. Surgery 1990;107(5):560-65 